\title{
Yo estudio para ser ingeniero: ¿para qué cursar administración y contabilidad?
}

\section{Study to be an Engineer. Why to Study Administration and Accounting?}

\author{
Javier Damián Simón Universidad del Papaloapan, Oaxaca, México \\ ORCID: http://orcid.org/0000-0002-2140-7622
}

Doctor en Enseñanza Superior por el Centro de Investigación y Docencia en Humanidades del Estado de Morelos. Master en Ciencias de la Educación por el Instituto de Estudios Universitarios A. C. y Master en Administración por la Universidad Autónoma de Guerrero. Profesor investigador adscrito al departamento de

Ciencias Empresariales de la Universidad del Papaloapan.

Recibido 04-07-18 Revisado 25-07-18 Aprobado 18-09-18 En línea 19-09-18

\section{*Correspondencia}

Email: damian_ce@hotmail.com

\section{Citar como:}

Damian Simon, J. (2018). Yo estudio para ser ingeniero: ¿para qué cursar administración y contabilidad? Propósitos y Representaciones, 6(2), 453-540 . Doi: http://dx.doi.org/10.20511/ pyr2018.v6n2.227

(C) Universidad San Ignacio de Loyola, Vicerrectorado de Investigación, 2018

(cc) BY-NC-ND Este artículo se distribuye bajo licencia CC BY-NC-ND 4.0 Internacional (http://creativecommons.org/licenses/by-nc-nd/4.0/). 


\section{Resumen}

Actualmente se impulsan temas transversales en el currículo de las ingenierías para otorgarles un valor agregado a sus egresados y para responder a las nuevas exigencias del mercado del trabajo. La investigación tuvo como objetivo principal conocer las opiniones de los estudiantes de ingeniería sobre el grado de contribución de las asignaturas económico administrativas en su formación académica. Mediante un estudio descriptivo con un enfoque cualitativo se estudiaron las opiniones de 23 estudiantes de ingeniería que cursaron durante un año las asignaturas de administración y contabilidad misma que forman parte de la currícula. Se encontró que los estudiantes muestran un desarrollo muy marcado de su identidad profesional como ingenieros lo que condiciona su nivel de aceptación de las asignaturas distintas a su perfil profesional, pues desde su imaginario no les otorgan utilidad alguna, sin embargo, cuando los profesores seleccionan apropiadamente los recursos didácticos y el proceso de enseñanza es ajustado a un perfil de ingeniería, los estudiantes empiezan a reconocer el aporte de dichas asignaturas en su formación universitaria mismas que les proporcionan las bases para enfrentarse a las nuevas exigencias como futuros ingenieros en actividades que van más allá de lo de carácter técnico.

Palabras clave: Formación en Ingenierías, estudiantes de ingeniería, administración, contabilidad. 


\section{Summary}

Currently, cross-cutting subjects are promoted in the engineering curriculum to give added value to their graduates and to meet the new demands of the labor market. The main objective of the research work was to know the opinions of the engineering students about the level of contribution of the administrative-economic subjects in their academic training. Through a descriptive study with a qualitative approach, opinions of 23 engineering students were studied. These students studied administration and accounting subjects, which are part of the curriculum, during a year. It was found that the students show a very marked development of their professional identity as engineers, which determines their acceptance level of the subjects different from their professional profile, since they think they are useless. However, when the teachers adequately select the didactic resources and the teaching process adjusted to an engineering profile, students start to recognize the contribution of these subjects to their university education, which provide them with the foundations to face the new demands as future engineers in not only technical activities.

Keywords: Engineering Training, Engineering Students, Administration, Accounting 


\section{Introducción}

Actualmente a nivel mundial se presenta en el escenario educativo de nivel superior la tendencia de formación multidisciplinaria, es decir, se procura que los futuros egresados además de ser especialistas en su campo también conozcan y apliquen métodos y técnicas de otras áreas o disciplinas que les sirvan de apoyo para poder desarrollarse en sentido laboral y profesional (Damián, 2016). Desde la década de los noventa del siglo pasado algunos teóricos empezaron a hablar de la desintegración de las carreras o profesiones de ingeniería meramente de orden técnico e identificaron la necesidad de reorientar la formación del ingeniero para constituirse según Sáez (2004), en un "ingeniero sociotécnico". Lo anterior aunado a que los estudiantes de ingeniería actuales pertenecen a la llamada generación $\mathrm{Z}$ que nacieron en el auge de la tecnología e internet y se caracterizan por ser personas interactivas y multifuncionales, pero que también tendrán que afrontar muchas dificultades para ingresar al mercado laboral (Geck, 2006), por lo cual las universidades donde se forman deben implementar diversas estrategias para el desarrollo del proceso de enseñanza aprendizaje que les permita apropiarse de una formación que vaya más allá de lo meramente técnico (Correia \& Bozutti, 2017; Vega, 2013).

\section{Flexibilidad laboral y nuevas exigencias en la formación universitaria.}

La organización del trabajo actualmente se caracteriza según Rodríguez (1995), por tres aspectos: 1) integrar las tareas en lugar de dividirlas, es decir, la especialización del trabajador ha pasado a un segundo plano; 2) otorgar a los trabajadores una mayor participación en la concepción, programación y evaluación de sus propias tareas vía la productividad y la eficacia y; 3) articular de manera más equilibrada las actividades desarrolladas en áreas específicas de gestión con la finalidad de trasladarlas al taller o a las líneas de producción. Ante estas nuevas exigencias del mercado de trabajo se hace necesaria la existencia de una fuerza de trabajo flexible, situación que liga 
a la educación superior con estas exigencias (Rodríguez, 1995), es decir, se apunta hacia una política de gestión del recurso humano basada en la polivalencia, la flexibilidad y una mayor cualificación lo que lleva implícito la existencia de un correlato con una nueva política educativa (Neffa, 1993).

Lo antes tratado para los diseñadores de las políticas de educación superior sólo son un ejemplo de los cambios que acontecen y que se deben tomar en cuenta para definir y organizar los programas curriculares universitarios a fin de que resulten pertinentes, ya que éstos deben brindar las condiciones necesarias a los egresados para insertarse en el mercado laboral o acceder a otros niveles de formación (Celis \& Gómez, 2005; Klink, Boon $\&$ Schlusmans, 2007). Las reformas de los sistemas educativos en el nivel universitario ante estos cambios y exigencias del mercado del trabajo, se consideran como la piedra angular en la formación de una fuerza laboral ampliamente cualificada y como una estrategia central para responder a dichas exigencias (Hirst \& Zeitlin; 1990,1991). Ante este nuevo escenario Gibbons et al. (1994), afirman que un segundo modo de producción de conocimiento está cobrando importancia en la sociedad actual junto al modo tradicional y disciplinario, la producción de conocimiento conforme al segundo modo comienza con problemas de índole aplicada para los cuales el conocimiento tiene que ser movilizado, es decir, debe reunir los conocimientos pertinentes de diferentes campos del conocimiento (multidisciplinariedad) y con frecuencia se basa en la labor intelectual en colaboración con agentes de distintas áreas o campos disciplinares.

Al respecto Teichler (1998), menciona al examinar las diversas propuestas formuladas en diversos países por el conjunto de empleadores, comités de especialistas que estudian el futuro de la educación superior y los investigadores que analizan las conexiones entre la educación superior y el trabajo, que estos tres agentes concluyen que se espera que los graduados universitarios sean polifacéticos en capacidades genéricas que atraviesen diferentes disciplinas y tengan nociones en campos de conocimiento que constituyen la base de diversas capacidades profesionales, por lo cual se 
espera que las universidades provean a quienes se forman en ellas de más oportunidades de aprendizaje interdisciplinario que en el pasado (Planas, 2014). Ante estas nuevas exigencias en la formación de los recursos humanos que se integrarán a las empresas, en la década de los noventa se avivó el debate en torno a las características y los posibles cambios en los perfiles profesionales que ofrecen las universidades en esta época de mundialización, de hiperdesarrollo de las tecnologías y de cambios notables en las formas de organización del trabajo en las empresas.

En sintonía con lo antes comentado Barrón (2005), al hacer una evaluación de los distintos cambios en la currícula universitaria en el contexto latinoamericano, menciona que a diferencia de la década anterior en la que la formación de profesionales se regía por los avances disciplinarios y por las exigencias del mercado de trabajo a partir de una política nacionalista, en los últimos años imperan los principios de eficiencia, eficacia y calidad, principios que se acuñan y surgen desde el seno de la gran empresa y que están siendo expresados en el ámbito curricular mediante la búsqueda de la polivalencia, del dominio de estrategias cognitivas, de la aplicación de herramientas conceptuales y metodológicas, del desarrollo de un pensamiento anticipatorio y propositivo y de un sentido emprendedor a fin de contar con egresados con una formación tanto especializada y técnica como multidisciplinaria. Por todo lo anterior se comprenderá fácilmente porque desde la década de los ochenta del siglo XX sobre todo en los países industrializados se empezó a vislumbrar la necesidad de adecuar las profesiones existentes a las nuevas exigencias del entorno (MEC, 1985), es decir, algunas profesiones tradicionales necesitaban reinventarse para continuar generando oportunidades de trabajo. A continuación se abordan las tendencias de cambio en algunas profesiones del área de ingeniería, como un preámbulo para entender el impulso que se está dando -desde la política educativa nacional- a la inclusión de temas administrativos y empresariales de manera específica y transversal en las diversas carreras de ingeniería. 


\section{Las profesiones de ingeniería y las nuevas exigencias.}

Algunas investigaciones efectuadas en Europa en la década de los ochenta del siglo XX sobre los egresados del área de ingeniería, concluyeron que éstos seguían "siendo demandados por el mercado de trabajo para puestos estrictamente técnicos, pero que se prefiere a los ingenieros con una plusformación" (MEC, 1985, p. 38). Por su parte Ruiz (1998), en un estudio que llevó a cabo sobre las funciones de los graduados de ingeniería industrial cuyo perfil profesional era llevar a cabo actividades tendientes a supervisar los procesos productivos en las plantas industriales, encontró que dicho perfil en la práctica profesional se modificaba según las nuevas exigencias de las empresas, pues un alto porcentaje de éstos profesionales asumían cargos de gestión del área económico-administrativa; seis años después Ruiz (2004), efectúa otra investigación sobre el tema encontrando que los egresados de ingeniería tienen que afrontar altas exigencias de índole personal, interpersonal y de temas de negocios en el desarrollo de sus actividades laborales, dichos resultados fueron confirmados por García y Romero (2011), quienes concluyeron que los ingenieros que trabajan en industrias maquiladoras tienen exigencias de habilidades técnico-administrativas mismas que no recibieron durante su formación universitaria. Para el año 2004 muchas profesiones enfrentaban problemas debido a la complejidad creciente del entorno siendo al mismo tiempo de índole técnica, politécnica y sociotécnica, y estos últimos se caracterizaron porque a "las dimensiones técnicas propias de las categorías anteriores se sumaron las múltiples y más complejas categorías de factores humanos y sociales, que requieren de profesionales híbridos" (Sáez, 2004, p. 2; Ruiz, 2004), era evidente la necesidad de efectuar cambios por lo que Williams (2004), habla de la desintegración de la ingeniería:

... lo que está desapareciendo es la ingeniería como profesión coherente e independiente caracterizada por las relaciones bien definidas con la industria y otras organizaciones sociales, con el mundo material y con los principios rectores tales como la funcionalidad; la ingeniería subsiste en 
un mundo híbrido en el que no existen fronteras nítidas entre la naturaleza autónoma no humana y los procesos generados por los humanos (p.40).

Se alude que ante estas nuevas exigencias los ingenieros no pueden seguir resolviendo los problemas únicamente desde el punto de vista técnico, sus ocupaciones exigen una mezcla de conocimientos técnicos, humanos y organizativos, es decir, "para prosperar en un mundo híbrido los futuros ingenieros deben hacerse híbridos" (Williams, 2004, p. 78). Lo anterior representa un reto para las universidades pues tienen que diseñar e implementar diversas estrategias didácticas y pedagógicas para impulsar y desarrollar habilidades administrativas en los alumnos que cursan programas de ingeniería, mismos que presentan resistencia al no poder identificar el aporte de dichas asignaturas para su formación profesional. Para que las universidades realicen cambios en sentido curricular a fin de formar a los futuros ingenieros para que responda a las nuevas exigencias de la sociedad y del mundo de los empleadores, es necesario conocer la situación que guardan las profesiones de la ingeniería en el ambo mundial y nacional, análisis que por razones de espacio se realiza de manera sucinta en los siguientes apartados.

\section{Las carreras de ingeniería en el ámbito internacional, su caracterización.}

De acuerdo con los resultados de Capote, Rizo y Bravo (2016), derivados del análisis de diversos reportes internaciones, la enseñanza de la ingeniería reclama necesidades y exigencias para que el proceso de formación responda a las exigencias del contexto, es decir, se demanda un proceso de enseñanza aprendizaje centrado en el estudiante, desarrollado de manera interactiva y colaborativa para que el futuro ingeniero adquiera un aprendizaje para toda la vida. Respecto lo anterior Moreno (2007), menciona la necesidad de formar ingenieros con conocimientos amplios y flexibles, con capacidades $\mathrm{y}$ actitudes para cumplir con sus responsabilidades sociales, es decir, que vaya más allá del dominio de las ciencias exactas. Para refrendar lo anterior 
Gómez, Castellanos y Delgado (2005), según varios documentos, eventos y experiencias nacionales e internacionales proponen que el ingeniero debe ser un profesional que cuente con:

1. Conocimiento profundo de las ciencias básicas, específicas y del ejercicio de la profesión, con una sólida formación teórica y científica general.

2. Vínculos estrechos con la industria con habilidades profesionales para resolver los problemas más generales y frecuentes del entorno social.

3. Formación integral, versátil y flexible con particular énfasis en sus capacidades de comunicación, de búsqueda, manejo, procesamiento y utilización de la información científico-técnica, dominio de TIC, conocimiento de lenguas extranjeras, formación económica, ecológica y humanista en general.

4. Formación cultural para desarrollar relaciones humanas sobre la base de conocimientos profesionales, sociales, ambientales, valores y sentimientos, ética profesional y autoestima.

5. Contar con un pensamiento lógico, heurístico, científico, sistémico, capaz de modelar sus ideas, flexible para asimilar los cambios rápidamente.

Para lograr lo anterior Restrepo (2007), afirma que es necesario que el currículo de ingeniería incluya los siguientes componentes básicos y garantice el alcance de los siguientes objetivos:

1. Privilegiar el componente formativo en ciencias básicas: Matemáticas, Física, Química e Informática (aprender a aprender de por vida).

2. Componente de formación específica con conocimiento suficiente en cantidad y calidad en la ingeniería de que se trate (aprender a hacer). 
3. Incluir formación complementaria en áreas de la economía, idiomas, social y administración (aprender a ser).

Diversas asociaciones tanto públicas como privadas que son o tienen una relación estrecha con el campo de trabajo del profesional de la ingeniería, están preocupados por la formación del ingeniero con un perfil profesional más integral que responda a las diversas situaciones o exigencias del mercado del trabajo y de la sociedad, a modo de ejemplo la Asociación Colombiana de Facultades de Ingeniería (ACOFI, 2007), menciona que actualmente la humanidad presenta grandes desafíos que son retos para los profesionales de la ingeniería: desarrollo sostenible, crecimiento, seguridad, progreso científico y tecnológico, entre otros y que están conscientes que para resolver dichas problemáticas se requiere un nuevo perfil del ingeniero caracterizado por una fuerte formación científica, intenso interés por la tecnología, ampliar y actualizar sus conocimientos, innovador y creativo, habilidad para comunicarse en varias lenguas, con espíritu emprendedor y empresarial, capacidad para transferir los avances tecnológicos y transformar insumos o materias primas en productos y servicios comercialmente viables, razones por las cuales han aparecido nuevos campos de actuación profesional para los ingenieros: financieros, administración y gerencia de negocios, medicina, política pública, por mencionar algunos ejemplos. Por su parte la UNESCO (2010), reconoce que la ingeniería, como un esfuerzo humano, se enfrenta a numerosos desafíos de su propia naturaleza tales como lograr más alianzas interdisciplinarias con las ciencias naturales, sociales y las artes; mejorar el enfoque en la innovación, espíritu empresarial, creación de empleo y promover la conciencia pública para el apoyo de la función social de la ingeniería.

\section{Las carreras de ingeniería en el ámbito nacional, su caracterización.}

El actual presidente de la Academia de Ingeniería de México (AIM) en diversas ocasiones ha mencionado la necesidad de establecer un nuevo perfil para el ingeniero mexicano para que responda a las exigencias de la sociedad 
particularmente para el conjunto de empleadores, así es necesario que en su formación se agreguen a sus conocimientos tradicionales nuevas habilidades y competencias para un ambiente productivo donde el sistema fordista ha dejado de ser la principal forma de su organización (Rascón, 2010); es decir, el campo de actuación de las ingenierías permea distintos escenarios y éstos le están demandado la inclusión transversal en los conocimientos técnicos y científicos de diversas habilidades gerenciales a fin de formar a un ingeniero con enfoque holístico caracterizado por una mentalidad flexible, conocimientos teóricos y técnicos sólidos y, con capacidad de liderazgo para conducir grupos de trabajo. Coincidentemente con lo anterior Smerdon (2000), afirma que el ingeniero actual debe convivir en comunidades diversas para atender y resolver problemas cotidianos y específicos, para lo cual debe mostrar su capacidad para comunicarse, trabajar en y liderar equipos multidisciplinarios, tener plena conciencia de las implicaciones sociales, ecológicas y éticas que implican los proyectos de ingeniería.

A fin de estructurar la nueva currícula para la formación actual del ingeniero mexicano Rascón (2010), enlista un conjunto de conocimientos, habilidades y destrezas requeridas para que el ingeniero responda a las exigencias actuales del sector laboral, de las cuales cuatro son del área económica administrativa:

1. Dominio teórico de matemáticas, física, química, biología, mecánica, materiales, ciencias de la ingeniería, economía, humanidades y ciencias sociales y, la forma de aplicarlos para resolver diversas problemáticas.

2. Habilidades para planear, diseñar, construir, supervisar, conservar y operar estructuras, instalaciones y diversos sistemas con un enfoque de sustentabilidad económica, social y ambiental.

3. Ser innovadores para integrar sus propuestas, ideas y las tecnologías en diversos campos de la sociedad en el sector público, privado y académico. 
4. Habilidad para enfrentarse y manejar el riesgo y la incertidumbre ocasionado por eventos naturales, accidentes y otras situaciones fortuitas derivadas del ejercicio de su profesión.

5. Mostrar liderazgo en las discusiones y decisiones en el diseño de políticas públicas que atañen a su área para el beneficio colectivo.

6. Habilidad para diseñar, realizar e interpretar trabajos y experimentos de campo en diversos contextos según el área de su especialidad, así como al interior de talleres y laboratorios.

7. Capacidad para utilizar un enfoque sistémico para diagnosticar, formular y solucionar problemas específicos y generales con sentido de responsabilidad social.

8. Saber comprender y evaluar el impacto de los proyectos de ingeniera en contextos globales y sociales.

9. Mostrar actitud y buena disposición para aprender a lo largo de su vida profesional para estar al tanto de las innovaciones en el área de su especialidad.

10. Capacidad para utilizar técnicas, herramientas y métodos modernos de ingeniería.

11. Desarrollar y mostrar habilidades emprendedoras, de creatividad y de gestión administrativa.

12. Manejo de información y diversos datos con gran percepción para interpretar diversas circunstancias sobre el entorno económicosocial-productivo.

13. Saber comunicarse perfectamente en español y conocer otros idiomas como el inglés para comunicarse en audiencias técnicas y no técnicas, de manera oral y escrita aprovechando los materiales audio-visuales. 
14. Mostrar capacidad para ejercer el liderazgo para trabajar y coordinar grupos heterogéneos, multidisciplinarios y en sitios, situaciones y contextos diferentes.

15. Capacidad para el dominio de las TIC en su campo de actuación profesional.

16. Aplicar en su desempeño profesional un pensamiento crítico y asertivo, con una mentalidad competitiva, prospectiva y proactiva.

17. Conducirse en su actuación laboral y personal con ética profesional, responsabilidad, compromiso, valores y vocación de servicio.

Además de todo lo anterior la Secretaria de Educación Pública del país (SEP, 2015), en el último estudio que llevó a cabo acerca de los estudios de ingeniería reportó que el crecimiento en la matrícula de estas carreras ha alcanzado casi el millón de estudiantes (superior a Estados Unidos de América, Japón y la Unión Europea); no obstante, dicho crecimiento y expansión de la matrícula está ocasionando diversos retos y oportunidades para los responsables de las políticas de educación superior y de las universidades del país, tal como lo reportan los diversos diagnósticos realizados por el Consejo de Acreditación de la Enseñanza de la Ingeniería (CACEI, 2014), entre los que destacan tres grandes retos: relativos a la matrícula, al proceso de formación y al campo de actuación profesional. En cuanto al primer reto relacionado con la matrícula se tiene que existe:

1. Abundantes programas de ingeniería con definiciones diferentes (916 denominaciones y 5,658 programas distintos).

2. Gran heterogeneidad de perfiles y modelos de formación según la universidad que la oferte, aun cuando se trate de la misma denominación (ASME, 2011).

3. Baja eficiencia terminal y alta reprobación de los estudiantes en ciencias básicas. 
4. Crecimiento y expansión de la matrícula en áreas nuevas de la ingeniería (cómputo, robótica, mecatrónica, petróleo, energías renovables, automotriz, aeronáutica, biomédica, biotecnología, nanotecnología, ambiental, entre otras) y disminución en aquellas que resultan prioritarias para el desarrollo económico del país (Álvarez, 2014) ${ }^{1}$. Aunado a lo anterior a partir del año 1999 se impulsan fuertemente en el país carreras de ingeniería en el área de empresas y negocios (gestión empresarial, innovación y desarrollo de negocios, financiera y administración), sobre todo en subsistemas de educación superior de naturaleza tecnológica como el Tecnológico Nacional de México, las Universidades Politécnicas y las Universidades Tecnológicas, tres subsistemas con presencia a lo largo y ancho del territorio nacional (Damián, 2017).

El segundo grupo de retos están relacionados con el proceso de formación del ingeniero donde se observa una incipiente vinculación con el sector productivo pues escasamente participa en el desarrollo de competencias de los estudiantes mediante proporcionar escenarios reales de aprendizaje en sus instalaciones. Una alta proporción de carreras de ingeniera no incluye las prácticas de los estudiantes durante y a lo largo de su formación limitándose a una breve actividad al cumplir todos los créditos académicos en un periodo denominado residencia profesional, prácticas profesionales, estadía o estancias profesional, entre otras denominaciones (Martínez, Damián \& Rodríguez; 2018) y, en cuanto al servicio social éstas son desarrolladas en dependencias gubernamentales de los tres niveles de gobierno llevando a cabo actividades muy diferenciadas y con casi nulo nivel de coincidencia con los estudios de ingeniería; luego entonces es fácil entender las causas por las cuales los estudios de opinión de los empleadores mencionan que

1 A modo de ejemplo Dorador (2014), habla de las carreras derivadas de Ingeniería Mecánica agrupándolas en cinco grupos: 1) Ingeniería en manufactura (áreas: diseño de herramientas, mejora de procesos y, diseño para ensamble y manufactura), 2) Ingeniería de materiales (áreas: materiales compuestos y, materiales plásticos), 3) Ingeniería de diseño y diseño mecatrónico (áreas: diseño de productos y, diseño de maquinaria y equipo), 4) Ingeniería en Termofluidos (áreas: control de emisiones y, modelado de flujos de fluidos y partículas) y, 5) Ingeniería en Mecatrónica (área: automatización industrial, control industrial de procesos y, robótica). 
los ingenieros recién egresados presentan un limitado conocimiento de las principales técnicas, procedimientos y equipamiento que requieren en su actuación profesional.

El tercer reto lo representa el campo de actuación profesional del ingeniero y su definición desde la estructura de los planes de estudio, para ello es necesario incluir en la currícula diversos temas que garanticen una sólida formación en ciencias básicas y ciencias de la ingeniería que coadyuven a incrementar su capacidad de empleabilidad y por ende una rápida inserción laboral. Al respecto el problema estriba en una discusión sobre la demarcación laboral de los ingenieros, la primera que denominaremos clásica o tradicional concibe a este profesional como "ingenieros de diseño", que buscan mediante su conocimiento teórico y práctico basado en las ciencias exactas cómo mejorar, innovar y desarrollar bienes y productos o bien solucionar diversos problemas de su área de interés, en tanto que la segunda de corte más moderna y actual los concibe como "ingenieros de gestión", es decir dedican su conocimiento y experiencia a dirigir proyectos, personas, equipos de trabajo y empresas. Por su parte Damián (2018), denomina al primer grupo "ingenieros de overol" cuyas funciones son primordialmente técnicas y en un segundo grupo están los "ingenieros de bata blanca" que asumen funciones de naturaleza administrativa llegando a invadir campos laborales de otras profesiones. Luego entonces para responder a estas tres grandes exigencias el CACEI propone un modelo para la formación del ingeniero en México (Tabla 1), mismo que debe estructurarse respetando los modelos curricular y pedagógico institucionales e integrado por cinco ejes principales: 


\section{Tabla 1.}

Ejes que se proponen para la formación del ingeniero en México.

\begin{tabular}{|c|c|}
\hline Ejes & Descripción \\
\hline Ciencia & $\begin{array}{l}\text { Sólidos conocimientos y habilidades de conceptos y soluciones teóricas de las } \\
\text { ciencias básicas (matemáticas, física y química) que habilitan al estudiante } \\
\text { para el uso de herramientas y habilidades matemáticas, lógico espaciales, } \\
\text { de razonamiento, para predecir y analizar escenarios, para analizar datos y } \\
\text { comprender los fenómenos químicos y físicos para la resolución de problemas } \\
\text { de ingeniería. }\end{array}$ \\
\hline $\begin{array}{l}\text { Ciencias de la } \\
\text { ingeniería }\end{array}$ & $\begin{array}{l}\text { Conjunto de herramientas técnicas y metodológicas de las distintas disciplinas o } \\
\text { ramas de la ingeniería que permiten la solución de problemas de ingeniería básica } \\
\text { y general para lo cual se requieren un manejo adecuado de las ciencias básicas } \\
\text { y un entendimiento del contexto social, ético, económico y político del entorno. }\end{array}$ \\
\hline $\begin{array}{l}\text { Ingeniería } \\
\text { aplicada }\end{array}$ & $\begin{array}{l}\text { Conjunto de conocimientos y habilidades que facultan al estudiante para } \\
\text { identificar y resolver un problema especializado de alguna rama de la ingeniería } \\
\text { en el que se tienen que hacer uso de los cuatro ejes anteriores en un entorno de } \\
\text { competitividad, eficiencia y apegándose a los principios éticos y normas de la } \\
\text { ingeniería. }\end{array}$ \\
\hline $\begin{array}{l}\text { Ciencias } \\
\text { económico } \\
\text { administrativas }\end{array}$ & $\begin{array}{l}\text { Conocimientos y habilidades del área económico administrativas cuyo objetivo } \\
\text { es coadyuvar para el estudiante comprenda el impacto del entorno económico en } \\
\text { los proyectos de ingeniería y planifique, gestione, administre y controle proyectos } \\
\text { y procesos y, evalúe e interprete resultados. }\end{array}$ \\
\hline $\begin{array}{l}\text { Ciencias sociales } \\
\text { y humanidades }\end{array}$ & $\begin{array}{l}\text { Disciplinas que estudian las manifestaciones y el comportamiento de la sociedad } \\
\text { y del individuo, que proporcionan al futuro ingeniero los conocimientos y } \\
\text { habilidades para comprender y analizar cómo funcionan las cosas, el contexto } \\
\text { y los individuos y que desarrolle habilidades humanísticas, éticas, sociales e } \\
\text { individuales mediante el estudio de filosofías, teorías, conceptos y soluciones } \\
\text { elementales enfocadas a la problemática social, humanística y económica del } \\
\text { mundo actual. }\end{array}$ \\
\hline
\end{tabular}

Fuente: tomado y adaptado de CACEI (2014).

Relacionado con lo anterior Covarrubias (1998), menciona que en el país son tres los documentos fuentes que han sido utilizados como una guía para hacer modificaciones a las currícula de las profesiones de ingeniería en aspectos relacionados con la formación, valores, actividades y ejercicio de la profesión (Tabla 2). 
Tabla 2.

Documentos eje para la integración de la currícula de ingeniería.

\begin{tabular}{|c|c|}
\hline $\begin{array}{c}\text { Nombre, fuente } \\
\text { y año }\end{array}$ & Aportes para la formación del ingenieros \\
\hline $\begin{array}{l}\text { "Tecnología y } \\
\text { Economía. La } \\
\text { relación clave", } \\
\text { OCDE, } 1992 .\end{array}$ & $\begin{array}{l}\text { Se discute la conceptualización de las ingenierías tomando en cuenta su } \\
\text { ubicación en el campo del conocimiento y de las profesiones. } \\
\text { Se distinguen dos grupo de ciencias: puras y de transformación, las primeras } \\
\text { enfocadas en explorar las fronteras del conocimiento teórico sin preocuparse } \\
\text { con su nivel de aplicación, en tanto las segundas enfocadas a resolver problemas } \\
\text { surgidos de la actividad social y económica. } \\
\text { Se concluye que las ingenierías no tienen una delimitación específica y se } \\
\text { mueven entre las ciencias puras y de transformación por lo cual los futuros } \\
\text { ingenieros necesitan de una formación multidisciplinaria a fin de contribuir en } \\
\text { la atención de necesidades sociales y económicas a través de las diversas ramas } \\
\text { o campos de la ingeniería. }\end{array}$ \\
\hline $\begin{array}{l}\text { "Memoria de } \\
\text { Congreso sobre } \\
\text { la formación } \\
\text { del ingeniero", } \\
\text { UNESCO, } 1997 .\end{array}$ & $\begin{array}{l}\text { Especialistas de todo el mundo discuten sobre la formación del ingeniero y } \\
\text { proponen un listado de atributos que debe tener este profesional, dentro de } \\
\text { la cuales destacan de acuerdo a los objetivos de este trabajo la creatividad y } \\
\text { espíritu innovador, capacidad de comunicación y formación multidisciplinaria; } \\
\text { a los que habrá que añadir la formación ética para el respeto de valores y el } \\
\text { medio ambiente en general. }\end{array}$ \\
\hline $\begin{array}{l}\text { "Proyecto } \\
\text { Valores". } \\
\text { COPARMEX, } \\
1997 .\end{array}$ & $\begin{array}{l}\text { Puesto que muchos profesionales de la ingeniería se desempeñan en empresas } \\
\text { privadas y otros son empresarios, se propone un ideario basado en valores pues } \\
\text { dada la crisis moral es urgente el retorno a los valores, así los ingenieros deben } \\
\text { cumplir sus funciones sociales en el marco de un conjunto de valores aceptados } \\
\text { por la sociedad. }\end{array}$ \\
\hline
\end{tabular}

Fuente: elaboración propia con datos de Covarrubias (1998).

En cuando a la temática antes expuesta se reconoce que en nuestro país las universidades públicas se han rezagado en cuanto a desarrollar un currículo para las áreas de ingeniería que contemplen la inclusión de temas administrativos y financieros, sólo las universidades privadas de élite están impulsando en gran medida esta política ${ }^{2}$, ofertando estudios como el de ingeniero químico administrador de quien se espera que sea un profesionista que diseñe, opere y administre los procesos químicos para promover el desarrollo sostenible basado en la aplicación de las ciencias naturales y de la ingeniería, considerando la productividad, el desarrollo tecnológico y la rentabilidad de las organizaciones y es capaz de modelar, desarrollar y

2 En este grupo se encuentran el Instituto Tecnológico y de Estudios Superiores de Monterrey, Universidad Iberoamericana, Universidad Anáhuac, Universidad la Salle, Universidad de las Américas, Instituto Tecnológico Autónomo de México, entre las IES privadas más destacadas. 
mejorar procesos y productos químicos tomando en cuenta consideraciones técnicas, económicas, sociales, culturales y éticas (ITESM, 2018); o bien el ingeniero mecánico administrador quien posee una sólida formación en ciencias e ingeniería, especializado en áreas relacionadas con el diseño, instalación, operación y mantenimiento de sistemas mecánicos; la integración de la manufactura y la administración de procesos productivos, para lo cual hace uso correcto de la ingeniería de producción, el aspecto financiero y el desarrollo sostenible (ITESM, 2018).

Sobre lo anterior Damián (2018), refiere que al parecer la universidades públicas forman a los "ingenieros de overol" y las universidades privadas a los "ingenieros de bata blanca", es decir, los primeros presentan una formación meramente técnica para efectuar trabajo duro en su especialidad y los segundos, además pueden asumir con facilidad puestos directivos y de gran responsabilidad en las organizaciones donde se inserten para el trabajo. Reconociendo lo anterior algunos subsistemas de educación superior en los programas educativos de ciencias de la ingeniería en sus diversas opciones han incluido ciertas asignaturas de corte económico administrativo con dos finalidades: 1) sentar las bases de los principios de emprendimiento de negocios y, 2) desarrollar habilidades mínimas de tipo administrativo en los egresados que les puedan ser requeridos en su actuación profesional (Romero, 2013).

En el caso concreto que nos ocupa, la Universidad del Papaloapan(UNPA) perteneciente al Sistema de Universidades Estatales del Estado de Oaxaca (SUNEO), siguiendo las políticas de dicho sistema establece que en todas las carreras de ingeniería la currícula incluya de cuatro a cinco asignaturas de corte económico administrativo (Seara, 2010). Cabe aclarar que en dichas carreras no se encuentran adscritos profesores con dicha formación profesional, las asignaturas son cubiertas por profesores (contadores y administradores) que pertenecen a la Licenciatura en Ciencias Empresariales quienes son invitados a apoyar en la impartición de las clases. De acuerdo a pláticas sostenidas con algunos de estos profesores se identificó una situación 
muy común entre los estudiantes de ingeniería: una apatía y desánimo por las asignaturas de naturaleza económico administrativas mencionando que ellos están formándose como ingenieros y que no encuentran ningún sentido en cursar estas materias que son de otro tipo de carreras ni conocen su grado de contribución en su formación académica, razón por lo cual se decidió llevar a cabo una investigación sobre dicha situación en los estudiantes de dos carreras de ingeniería que se ofertan en la UNPA. Como es fácil de entender esa opinión, percepción o actitud de naturaleza negativa de los estudiantes hacia la inclusión de temas económico administrativo en su formación como ingenieros ocasiona dos situaciones: dificultad en los docentes para impartir dichas asignaturas ante estudiantes que se oponen a dicha formación y, escaso nivel de aprovechamiento de los contenidos de dichas asignaturas por parte de los estudiantes ocasionado por los bajos niveles de importancia atribuidos a éstas. El objetivo principal del trabajo es conocer cómo perciben los estudiantes de ingeniería a las asignaturas económico administrativas que forman parte de la currícula universitaria en cuanto al nivel de contribución para su formación académica y futuro desarrollo profesional y laboral $\mathrm{y}$, en segundo lugar, conocer como evalúan al trabajo docente en cuanto al desarrollo de los contenidos de dicha asignaturas a fin de poder hacer propuestas didácticas en el futuro.

\section{Método}

\section{Tipo de estudio y participantes.}

El estudio fue descriptivo utilizando un enfoque cualitativo. Debido al pequeño número de alumnos matriculados se optó que participaran todos en el estudio tal como lo recomienda Hernández, Fernández y Baptista (2014), siendo los que cursaron el sexto y séptimo semestre de Ingeniería en Alimentos (IA) e Ingeniería en Biotecnología (IB) que oferta la Universidad del Papaloapan. Cabe precisar que debido a la escasa matrícula en los semestres de las dos carreras, para las clases se reunían a los 23 alumnos en 
una sola aula. La tabla 3 muestra la composición de cada carrera así como las asignaturas del área económica administrativa que están incluidas en la currícula de las mismas.

\section{Tabla 3.}

Características de los participantes en el estudio.

\begin{tabular}{lcl}
\hline Carrera & $\begin{array}{l}\text { No. de } \\
\text { alumnos }\end{array}$ & Asignaturas del área económica administrativa \\
\hline $\begin{array}{l}\text { Ingeniería en } \\
\text { Biotecnología. }\end{array}$ & 11 & $\begin{array}{l}\text { Administración*, Contabilidad**, Mercadotecnia y, Formulación y } \\
\text { evaluación de proyectos. }\end{array}$ \\
$\begin{array}{l}\text { Ingeniería en } \\
\text { Alimentos. }\end{array}$ & 12 & $\begin{array}{l}\text { Teoría económica, Administración*, Contabilidad**, Estructuras } \\
\text { administrativas, Formulación y evaluación de proyectos y, Dirección } \\
\text { general. }\end{array}$ \\
\hline
\end{tabular}

* Cursada en sexto semestre; ** Cursada en séptimo semestre

Fuente: elaboración propia con datos de la investigación

\section{Forma de desarrollo de las actividades durante el año escolar.}

El primer día de clases antes del encuadre del curso se realizó una plenaria donde se solicitó a los alumnos que expresaran su opinión acerca de las asignaturas del área económico administrativa que cursarían (los resultados de la plenaria se discuten en otro documento), con la finalidad de obtener información para adaptar los contenidos y seleccionar las estrategias didácticas que contribuyeran a que los estudiantes rompieran sus paradigmas respecto a la nula utilidad de este tipo de asignaturas en su formación como ingenieros. En términos generales comentaron que esas asignaturas no tenían valor para ellos, que estaban de más, que eran "relleno", que no les atraían y que de acuerdo a los comentarios de compañeros de semestres más avanzados las clases eran aburridas y que los profesores los trataban como si fueran estudiantes de la Licenciatura en Ciencias Empresariales (carrera a la que están adscritos los profesores).

Se platicó con algunos profesores que en el pasado trabajaron con los estudiantes de ingeniería y se encontró que utilizaban las mismas estrategias 
didácticas para desarrollar los contenidos tal como lo hacen con los estudiantes de LCE y que los recursos bibliográficos son los libros de texto básicos para la formación del administrador o contador.

Con la información anterior se efectuaron ajustes para desarrollar los contenidos de las asignaturas, se decidió no utilizar los libros de texto propios del contador y del administrador y se sustituyeron por otros más acordes a su perfil, se utilizaron a lo largo del curso de administración dos libros de texto: 1) "Administración para ingenieros" de Miguel Rojas editado por la Facultad Nacional de Minas de la Universidad Nacional de Colombia, que a lo largo del texto utiliza la denominación de "ingeniero administrador" destacando que en la medida que transcurre el tiempo en su trayectoria laboral todo ingeniero necesitar conocer y aplicar conceptos y técnicas provenientes de las ciencias administrativas y de los negocios y, 2) "Los siete hábitos de la gente altamente efectiva" de Stephen Covey que abunda en la importancia de conocer y aplicar principios para la construcción de la autoconfianza, carácter, integridad, honestidad y la dignidad humana como insumos básicos para transformar nuestro ámbito laboral, social y personal. Para el caso del curso de Contabilidad de igual manera se dejaron de utilizar los libros que se utilizan en la formación del contador y se utilizaron diversos materiales diseñados como manuales del participante en cursos y talleres de "Contabilidad para no contadores", dirigidos a personas no expertas en el tema o sin ninguna formación académica pero que les permite conocer todo lo necesario sobre la técnica contable, sin complejidades, sin la obsesión de la cátedra especializada o hacerlo de manera árida pero, sin olvidar todo lo que resulta esencial para el ingeniero administrador.

\section{Forma de obtención de la información.}

Una vez finalizados los dos semestres se les solicitó a los estudiantes que elaboraran un escrito de manera libre de dos cuartillas máximo donde expresaran sus opiniones sobre el aporte de las asignaturas del área 
económica administrativa para su formación profesional y laboral. Esta actividad se realizó una vez finalizadas todas las evaluaciones de los cursos con la finalidad de evitar sesgos en las opiniones de los estudiantes por temor a posibles represalias por lo que comentaran. El escrito lo enviaron al correo electrónico del profesor quien los recuperó y organizó para su lectura y análisis respectivo.

\section{Análisis y tratamiento de la información.}

Se procedió a la lectura de cada uno de los 23 escritos a fin de tener un conocimiento muy general de las opiniones de los estudiantes y empezar a identificar patrones de opiniones. En una segunda lectura se identificaron y establecieron las categorías de análisis que permitieron evaluar el sentido de las opiniones de los estudiantes acerca del nivel de importancia que otorgaban a las clases de administración y contabilidad (Fox, 1981; Espín, 2002). Se realizó una interpretación a nivel manifiesto utilizando los fragmentos de las opiniones de los estudiantes tal cual lo expresaron en sus escritos, para ello en cada fragmento se coloca su nombre seguido de la siglas IB e IA según la carrera que cursa: Ingeniería en Biotecnología e Ingeniería en Alimentos; también se llevó a cabo una interpretación a nivel latente tratando de interpretar, construir y darle sentido a sus opiniones a través de la teoría existente sobre el tema tal como lo mencionan Alvarez-Gayou (2005) y Bogdan y Biklen (1992).

\section{Resultados}

Los resultados obtenidos se presentan en seis secciones en las que se alude y describe a la misma cantidad de categorías que emergieron del análisis de contenido de los documentos escritos por los estudiantes. Primeramente la tabla 4 muestra el resumen de las categorías y la cantidad y proporciones de menciones que se hicieron de éstas de acuerdo a la carrera que cursan los estudiantes. 


\section{Tabla 4.}

Alusión a las categorías de acuerdo a la carrera que cursan los estudiantes.

\begin{tabular}{lcc}
\hline \multicolumn{1}{c}{ Categorías } & \multicolumn{2}{c}{ Número de menciones y proporción (\%) por carrera } \\
\cline { 2 - 3 } & Ingeniería en Biotecnología & Ingeniería en Alimentos \\
\hline Trabajo en el aula & $3(27 \%)$ & $9(75 \%)$ \\
Utilidad de las asignaturas & $8(72 \%)$ & $3(25 \%)$ \\
Identidad profesional & $6(54 \%)$ & $2(17 \%)$ \\
Aspiraciones laborales & $4(36 \%)$ & $1(8 \%)$ \\
Objetivos de la asignatura & $3(27 \%)$ & $1(8 \%)$ \\
Preconcepciones & $3(27 \%)$ & $2(17 \%)$ \\
\hline
\end{tabular}

Fuente: elaboración propia con datos de la investigación

\section{Categoría 1. Preconcepciones hacia las asignaturas económico administrativas.}

Esta categoría muestra que los estudiantes presentan antes de los cursos preconcepciones de naturaleza negativa o errónea hacia las asignaturas del área económico administrativas, conocer lo anterior resulta de importancia para la labor docente pues de acuerdo con Martínez (2004:181), la actitud está referida a "las concepciones fundamentales relativas a la naturaleza del ser humano, misma que implica ciertos componentes morales o humanos, exige un compromiso personal y se define como una tendencia o disposición constante a percibir o a reaccionar en un sentido determinado, a saber: tolerancia e intolerancia, de respeto o de crítica, de confianza o de desconfianza, etc.". Así tenemos que algunos estudiantes reconocieron que cursar estas asignaturas les representó un reto a sus preconcepciones como es el caso de Erick y Azucena estudiantes de Ingeniería en Biotecnología quienes mencionaron:

Sinceramente a mí nunca me había gustado el área administrativa, yo era de los que decía "voy a ser un ingeniero, eso a mí no me sirve", pero conforme las clases fueron avanzando me fui dando cuenta de lo importante que es en la actualidad contar con conocimientos de estas áreas (Erick, IB). 
En el curso de administración al comienzo no me sentía muy cómoda con los temas de administración ya que no los comprendía y porque era algo diferente a lo que yo estaba acostumbrada a escuchar (Azucena, IB).

Para otros estudiantes no les representó ningún reto, simplemente el cursar este tipo de materias les resultaba algo diferente o fuera de lo ordinario tal como lo refiere una estudiante de Ingeniería en Alimentos:

... todo empezó con curiosidad por algo nuevo que no conocía y un poco de miedo y sin embargo fue muy interesante la asignatura porque de igual manera [el profesor] tenía una forma de explicar muy eficiente (Paula, IA).

No obstante, tal como lo reportan Romero, Utrilla y Utrilla (2014), los resultados muestran que dichas preconcepciones iniciales de naturaleza negativa fueron cambiando a medida que se desarrollaron los temas de las asignaturas de acuerdo a la forma de trabajo que se explicó en el apartado de metodología, es decir, los estudiantes de ingeniería que al principio mostraron actitudes de carácter negativo hacia la materia y hacia el profesor lograron entender que el cursar dichas asignaturas les reportaba ciertos beneficios, entre los cuales señalaron los siguientes:

[Al término del curso] ves la problemática desde un punto de vista diferente al tuyo, inclusive te das cuenta de cosas que al menos yo ignoraba (Eliza, IA).

El haber tomado esta clase me sirvió de mucho porque ahora tengo en cuenta las áreas para laborar, ya que en un principio tenía la idea que un ingeniero solo podía laborar en procesos de producción tecnológicas, mantenimiento de máquinas y cosas así, ahora comprendí que para muchos ingenieros el éxito de la carrera puede ser obtener una posición de mando, una posición de mayor jerarquía (Mayra, IB). 


\section{Categoría 2. Utilidad atribuida a las asignaturas económico administrativas.}

Esta categoría se subdivide en tres grupos de acuerdo al tipo de utilidad atribuida por los estudiantes: personal, académico y profesional-laboral. Se considera un factor clave para cursar con éxito y aprovechar los contenidos temáticos de las asignaturas que distan de la formación de ingeniería, que los estudiantes encuentren sentido a dichas asignaturas pues son también una motivación para el aprendizaje (Tapia, 2005). De acuerdo con Covington (2000) y Eccles y Wigfield (2002), en general los estudiantes suelen afrontar sus trabajos y deberes escolares con más o menos interés y esfuerzo debido a tres factores: 1) sus percepciones acerca de la utilidad de aprender lo que se les propone, misma que depende de sus metas, objetivos e intereses particulares; 2) sus expectativas para afrontar con éxito las dificultades para lograr los aprendizajes propuestos por los profesores y; 3 ) los costos (tiempo y esfuerzo), que tiene que invertir para lograr los aprendizajes perseguidos. En cuanto a la utilidad de naturaleza personal se encontró que algunos estudiantes consideran que las asignaturas económico administrativas les proporcionaron herramientas y consejos prácticos para planificar y organizar sus diversas actividades personales, para la correcta administración de sus recursos monetarios y hasta generar la idea de un negocio propio dentro de su área de ingeniería tal como le refieren los siguientes estudiantes (tabla 5): 


\section{Tabla 5.}

Utilidad de naturaleza personal atribuidas a las asignaturas económico administrativas.

1. Desde mi punto de vista si es importante llevar estos cursos como base para la planeación u organización de uno mismo, y además de que los conocimientos adquiridos serán importantes para el futuro y poder desenvolverse cada vez más y sobre todo porque se aprenden nuevas técnicas y formas de trabajo que pueden ayudar más a la productividad (Paula, IA).

2. Creo que es una materia que se aplica de buena manera para que nosotros como estudiantes tengamos una idea de cómo manejar mejor nuestro dinero, tiempo y aptitudes, tener la noción el día de mañana que queramos ser emprendedores. Hay muchos aspectos que yo desconocía y que te hacen ver que realmente el tener conocimiento de esto te ayudaría en tu negocio por muy pequeño que sea, cada punto abordado en la materia fue de gran ayuda ya que te hace tener una visión colocándote distintos ejemplos muy fáciles de entender (Rosa, IB).

Fuente: elaboración propia con datos obtenidos de los estudiantes.

Por otra parte se encontró que los estudiantes mencionaron que las asignaturas económico administrativas presentan una utilidad de tipo académica como factor de valor agregado en su formación como futuros ingenieros pues éstas les permitían ahora el poder entender de manera más amplia la situación de los negocios (tabla 6): 


\section{Tabla 6.}

\section{Utilidad académica atribuida a las asignaturas económicas administrativas.}

1. ... y aunque mi carrera sea enfocada más al aérea de producción, de desarrollo de nuevos productos, de calidad e inocuidad de alimentos, no es menos importante las asignaturas de nivel administrativo, como contabilidad, teoría general de sistemas y administración (Karen, IA).

2. ... pienso que al ingeniero en formación se le da un mejor panorama de lo que se enfrentará en la vida real de la empresa. Por eso estoy de acuerdo con la globalización de las carreras de ingeniería en el aspecto académico, buscar nuevas materias para formar un ingeniero humano que sepa cómo tratar a las personas a su cargo y llevarlas por el camino de la producción óptima de la empresa (Jorge, IB).

3. Creo que conocimientos nuevos como los administrativos impartidos a los ingenieros, son parte de la forma de vida laboral actual, ya que así como existen avances en las industrias para tener mayor eficacia en producción, en las instituciones [educativas] también existen modificaciones en los modelos educativos que están ligados con los requisitos pedidos en las industrias y para ampliar más el conocimiento de los ingenieros (Azucena, IB).

4. Estos cursos te sirven en gran medida para una mejor organización dentro de la empresa y de esta manera llevar un control de todo lo que se desea desde un principio, es decir, cada empresa o industria tiene un objetivo, una misión y propósito, y es aquí donde entra el saber tomar las decisiones correctas desde la perspectiva que nos ofrece la administración todo eso se podría lograr con la realización del trabajo en equipo, aprovechando todos los conocimientos y habilidades de cada integrante; es aquí donde se podría decir que ambas partes ganan ya que si logra por ejemplo en la industria de alimentos que el producto salga al mercado se obtendrían mayores ganancias y los empleados estarían con un mejor sueldo (Zenaida, IB).

Fuente: elaboración propia con datos obtenidos de los estudiantes.

En un tercer grupo algunos estudiantes mencionaron que las asignaturas económico administrativas representan una utilidad de tipo profesionallaboral pues les permitían ahora entender que en su campo de actuación profesional como ingenieros es necesario contar con conocimientos básicos de este tipo de asignaturas mismas que les otorgan un valor agregado a su formación profesional tal como se muestra en los siguientes comentarios (tabla 7): 
Tabla 7.

Utilidad profesional-laboral atribuida a las asignaturas económicas administrativas.

1. Es importante porque... las actividades y roles de los ingenieros en las empresas actuales está muy diversificada, por tanto el ingeniero debe tener un conocimiento multidisciplinario e integral para poder cubrir con esa demanda, además que es requisito indispensable que piden las empresas en la actualidad ya que ellas al igual que la tecnología están en constante cambio y se reestructuran para poder ser eficientes y poder competir en el mercado, entonces, nosotros como ingenieros de estos nuevos tiempos tenemos que ajustarnos a estas demandas y estar preparados para las exigencias que se generan en un mundo tan cambiante como el nuestro (Eliza, IA).

2. Es importante para nosotros los ingenieros llevar cursos del área económico-administrativa para fortalecer nuestra profesión, me atrevo decir que somos más eficientes que muchas personas que tienen una carrera administrativa, incluso podremos fungir mejor después de que hayamos tenido una experiencia laboral ya que con los conocimientos de estas asignaturas se nos facilitará el relacionarnos con las personas y transmitir la información a los demás (Eligio, IB).

3. La importancia de llevar cursos del área administrativa recae en la multidisciplinariedad del ingeniero, quizás desde el punto de vista como estudiante me parecía innecesario, pero a través del tiempo comprendí que es necesario y fundamental tener una preparación completa de calidad no solo para mi persona, sino para el bien de la sociedad que me rodea, para sobresalir y ser mejor cada día, el conocimiento es una virtud y nunca es malo aprender más, muy aparte de que, al tener estos conocimientos puedo desempeñar un mejor papel laboral (Leo, IB).

4. En los nuevos puestos ocupacionales y profesionales de la ingeniería, resalta la importancia que tiene el enfoque de los conocimientos económico-administrativo logrando preparar ingenieros más predispuestos a desempeñarse en las tareas que realiza el ingeniero de cuello blanco y manos limpias, en tanto que manifiestan tener una mejor preparación y actitud para responsabilizarse de esas actividades que poco tienen que ver con el sistema de conocimientos que establece la disciplina de la ingeniería y, en cambio, demandan conocimientos técnicos poco profundos, además de amplias habilidades sociales, necesarias en el desarrollo de un capital social provechoso tanto para la empresa como para el ingeniero en lo personal (Mayra, IB).

5. ... así tendremos más oportunidades de trabajo por que podremos desempeñarnos en cualquier área de la empresa, obviamente no como la haría alguien especializado en esa área, pero las empresa nunca están dispuestas a gastar más de lo que no estiman y así contratarán a un ingeniero ya que puede cumplir dos funciones la de ingeniero y la de organizar a las personas a su cargo (Jorge, IB).

6. En mi opinión el llevar cursos del tipo económico administrativo son una herramienta más para que el ingeniero puede desempeñar [otros trabajos], para tener una visión más amplia de lo que ocurre del otro lado de la moneda de la empresa, sin embargo, no debería ser algo en lo que el ingeniero dedique todo su tiempo ya que sus conocimientos se requieren más en la producción (Azucena, IB).

7. ... que son muy importantes para nuestras bases como ingenieros ya que... a los ingenieros les hace falta un poco más de unión grupal, aprender a trabajar en equipo ya que son las fortalezas que pueden llegar a presentarse en una empresa incluso a nivel profesional o laboral, el hecho de congeniar con los compañeros de trabajo trae una armonía (Keyla, IB).

Fuente: elaboración propia con datos obtenidos de los estudiantes. 


\section{Categoría 3. Objetivos atribuidos a las asignaturas económico administrativas.}

Esta tercer categoría da cuenta del nivel de conocimiento que presentan los estudiantes acerca de los objetivos que persigue el programa de estudios al incorporar asignaturas económicas administrativas dentro su currícula universitaria; lo anterior se considera favorable pues si los estudiantes reconocen que los objetivos constituyen la finalidad principal del acto educativo y que se relacionan con las capacidades o competencias que se pretende desarrollar en ellos estarán más dispuestos a abordar y estudiar los contenidos temáticos específicos de dichas asignaturas tal como lo refiere Murillo (2010). Así tenemos que para algunos estudiantes sobre todo de ingeniería en alimentos, este tipo de asignaturas tienen el objetivo de impulsar una cultura emprendedora a fin de que ellos al egresar identifiquen oportunidades de negocios mediante el aprovechamiento integral de los diversos recursos disponibles en la región tal como lo expresaron a continuación (tabla 8):

\section{Tabla 8.}

El emprendimiento como objetivo de las asignaturas económico administrativas.

1. ... sé que nos imparten materias ajenas a nuestra carrera con el objetivo de que si nosotros no queremos laborar o servirle a un jefe, nosotros mismos podamos ser nuestros propios jefes ya sea mejorando o elaborando un producto innovador o dando un servicio sea cual sea nuestra idea (Karen, IA).

2. ... del curso me llevo una buena impresión pues a pesar de que no se relaciona directamente con nuestro perfil de ingeniería es bueno y esencial en la formación, ahora tengo el conocimiento para hacer mi propia empresa cuando termine y eso me agrada, deberían agregar más materias de este tipo que te ayuden a abrir tu panorama y no quedarte solo con la idea de que estas solo para producir y ya (Jorge, IB).

Fuente: elaboración propia con datos obtenidos de los estudiantes. 
Otro grupo de estudiantes refieren lo que menciona Salcedo (2011), en el sentido de que están conscientes de que los objetivos de este tipo de asignaturas no sólo se refieren a formulaciones de carácter didáctico sino a los cambios de conducta futuros que se espera de ellos como efecto del proceso de enseñanza aprendizaje, traducidos en el desarrollo de otro tipo de conocimientos y habilidades que les permitan ampliar su campo de actuación profesional como ingenieros en el mundo del trabajo tal como se muestra en los siguientes comentarios (tabla 9):

\section{Tabla 9.}

Ampliar el campo laboral como objetivo de las asignaturas económico administrativas.

1. El propósito de estas asignaturas es que los ingenieros consideren que pueden desempeñarse al menos en dos niveles de administración: una referida a la administración técnica, es decir, ligada a la producción, responsable de diseñar la logística necesaria en el proceso de producción y el segundo nivel estaría relacionado con la administración, o sea la gerencia general de la empresa y en algunos de sus ámbitos: comercialización, compras y relaciones con proveedores, recursos humanos, etc., cuyo desempeño requeriría del dominio de otros conocimientos y de mayores dosis de capacidades sociales (Mayra, IB).

2. La administración es una forma de planear, organizar, tener una dirección y llevar un control de los objetivos, esto con el fin de aprovechar mejor los recursos de una empresa por eso no está de más que los ingenieros adquieran conocimientos en esta área para mejorar sus aprendizajes y poder obtener un empleo de calidad (Zenaida, IB).

Fuente: elaboración propia con datos obtenidos de los estudiantes.

\section{Categoría 4. Identidad profesional del ingeniero.}

Esta categoría nos ayuda a explicar las razones por las cuales los estudiantes presentan una resistencia para las asignaturas económico administrativas, ya que a pesar de cursar apenas un poco más del 50\% de los créditos de su carrera de ingeniería han desarrollado fuertemente el sentido de pertenencia con ella, es decir, muestran una identidad profesional muy marcada entendida como aquella representación que se crea alrededor de un campo específico de labor el cual se reconoce en la sociedad, $\mathrm{y}$ entre un grupo de individuos que se identifican como miembros del mismo, cuya característica es compartir dicha representación social de la profesión y su sentido de 
pertenencia (Ávila y Cortés, 2007). Así en este sentido los estudiantes asumen una identidad profesional con una posición firme y dura considerando a las asignaturas económico administrativas como intrusas o con poco valor para su formación como ingenieros tal como lo expresan categóricamente a continuación (tabla 10):

\section{Tabla 10.}

Las asignaturas económico administrativas antagónicas con la identidad profesional.

1. ... creo que cuando estudias ingeniería para ti solo se te viene el mejoramiento de procesos, el saber mejorar el proceso de algo para obtener un mejor producto o lo que desees obtener y eso es lo que nos enseñan en la institución en donde estoy, como ser un ingeniero (Aridaith, IB).

2. ... uno no estará de lleno en la parte administrativa,...los ingenieros sólo deben estar en su área y no salir de ella, eso es tener respeto a los ingenieros (Eligio, IB).

3. ... antes de ser cualquier otra cosa "somos o seremos ingenieros", y como tal, la función principal de un ingeniero es la resolución de problemas de manera precisa y efectiva sin importar el método a utilizar, por esta razón la multidisciplinariedad en nuestra carrera es necesaria para poder realizar aquellas tareas que se le imponen a un ingeniero (Leo, IB).

4. La palabra ingeniero desde siempre ha causado admiración y respeto en la sociedad, porque son personas bien preparadas académicamente y se le liga a su exclusiva participación en tareas relacionadas con la innovación, diseño y operación de tecnologías en la sociedad,...pero si pueden integrar más materias como: administración, contabilidad, etc., obviamente no serán como materias de especialidad, sino como cursos de un semestre solo para tener el conocimiento [básico] de todo lo que se hace en la vida real en un empresa para así producir ingenieros de calidad y cuando se enfrenten a algún problema administrativo tengan la idea de cómo resolverlo (Jorge, IB).

Fuente: elaboración propia con datos obtenidos de los estudiantes.

En esta categoría también se encontraron estudiantes que asumen su identidad profesional pero muestran una postura blanda o tolerante al hecho de que tengan que cursar asignaturas económico administrativas, es decir, tal como lo menciona Miejers (1998), cuando el estudiante tiene plena conciencia de la carrera universitaria que cursa o conoce el papel que jugará con su formación profesional en el entramado del campo profesional, esto le transmitirá seguridad al egresar pues sabe cuáles son las diversas actividades que puede desempeñar y en qué puestos o áreas puede ser ubicado en las 
empresas, en el caso que nos ocupa tal como se ha encontrado en algunos estudios con egresados universitarios con formación multidisciplinar (Damián, 2016), algunos estudiantes consideraron que dichas asignaturas les otorgan un valor agregado a su formación universitaria misma que será de utilidad para su campo de trabajo, tal como lo muestran los comentarios siguientes (tabla 11):

\section{Tabla 11.}

Las asignaturas económico administrativas y su aporte a la identidad profesional.

1. Tomar cursos económico-administrativos nos permite aprender diferentes aspectos de esta área aunque no específicamente tendremos que ejercer en éstas, sino que nos proporcionan un conocimiento básico para interpretar situaciones o problemas administrativos relacionados en nuestra vida laboral (Paula, IA).

2. ... en una empresa existen tantos ingenieros ocupados en el área administrativa como ingenieros encargados de realizar las tareas específicas del proceso de producción, el manejo de la maquinaria y equipos, actividades de mantenimiento y supervisión, el "quehacer sucio", que inclusive se encargan de algunas labores de corte administrativo, dirigidas únicamente al proceso productivo, sin ir más allá de lo que la planta industrial exige (Mayra, IB).

3. Para el trabajo que desarrolla cualquier ingeniero, independientemente si es en la Industria o en su propia empresa, indiscutiblemente requiere estar capacitado para implementar técnicas que le permitan la simplificación del trabajo, planear, organizar y controlar la producción de bienes y servicios en condiciones óptimas de calidad, así mismo administrar eficazmente los recursos disponibles a fin de incrementar su productividad, rendimiento y rentabilidad,... afortunadamente todos los que estamos involucrados con el área de ingeniería debemos tener siempre presente que: es más fácil para un ingeniero ser administrador, que para un administrador ser ingeniero (Erick, IB).

Fuente: elaboración propia con datos obtenidos de los estudiantes.

\section{Categoría 5. Aspiraciones laborales.}

En esta categoría se encontró que no obstante que los estudiantes presentan un buen nivel de desarrollo de su identidad profesional como futuros ingenieros, están conscientes que las materias económico administrativas desempeñarán algún papel de importancia para ellos en su campo de trabajo, es decir, sus opiniones concuerdan con lo que mencionan Pastor, Peraita y Zaera (2013), en el sentido de que sus 
estudios universitarios de ingeniería con la inclusión de dicha asignaturas además de formarles como capital humano, aumentan su productividad y el atractivo para las empresas, incrementando su empleabilidad, tal como algunos de ellos comentaron (tabla 12):

\section{Tabla 12.}

\section{Las asignaturas económico administrativas y su aporte para la empleabilidad.}

1. ... pienso que nuestro sistema educativo se ha enfocado a que se formen alumnos de calidad no solo en el ámbito de ingeniería sino en otras aéreas que nos ayuden a ser mejores cada día, ya que se ha venido tomando en cuenta la opinión de las personas de afuera, o sea las empresas donde al concluir nuestros estudios trabajaremos (Karen IA).

2. La industria o empresa quiere a alguien que tenga conocimientos económico-administrativos, así que para que podamos encontrar un empleo y competir por el con los demás debemos de tener más conocimiento en esa área, así que es importante tener este tipo de cursos para todo ingeniero que quiera ejercer en la industria (Aridaith, IB).

3. ... es importante tener conocimientos del área administrativa ya que la industria está requiriendo ingenieros capacitados en estas áreas, y contando con una formación más completa nos abre un panorama aún más amplio a la hora de buscar un empleo, en comparación que solo teniendo exclusivamente la identidad del ingeniero como experto tecnológico desligado del área administrativa (Erick, IB).

Fuente: elaboración propia con datos obtenidos de los estudiantes.

Por otro lado otros estudiantes opinan que las asignaturas económico administrativas asignan valor agregado a sus estudios de ingeniería pues apuntan a que éstas pueden tener efectos positivos sobre la propensión al emprendimiento y que aumentan la probabilidad de alcanzar puestos directivos coincidiendo con lo reportado por Congregado et al (2008), desde su imaginario mencionaron lo siguiente (tabla 13):

Tabla 13.

Las asignaturas económico administrativas como valor agregado en el ingeniero.

1. ... el área administrativa donde se lleva a cabo la toma de decisiones es de mayor prestigio para un ingeniero, llegar a ésta área sería un éxito es su carrera (Mayra, IB).

2. Yo quiero trabajar en la industria y esto me da puntos para aspirar a conseguir un puesto más alto. La combinación de las áreas administrativas, técnicas y científicas enseñadas en la universidad serán nuestras mejores herramientas para competir con ingenieros egresados de universidades públicas de mayor renombre del país (Erick, IB).

Fuente: elaboración propia con datos obtenidos de los estudiantes. 
Sólo de manera muy escasa los estudiantes coinciden con Pérez et al (2012), al considerar que las asignaturas económico administrativas en su educación universitaria generaría en el futuro efectos positivos sobre las características del empleo o trabajo, es decir, empleos más estables, menos riesgo de paro, periodos de desempleo con duración inferior a la media y más posibilidades de lograr contratos indefinidos tal como lo indican los siguientes comentarios:

Las materias económico-administrativas en las carreras de ingeniería destacan por el hecho de que se tendría una mayor oportunidad de empleo en las industrias, es decir, un trabajo seguro, con buenas prestaciones (Zenaida, IB).

\section{Categoría 6. Trabajo en clases.}

Resulta de interés conocer las opiniones de los estudiantes acerca de la forma de desarrollar los contenidos temáticos de las asignaturas económico administrativas, con el fin de que los docentes las tomen en cuenta como insumos para la planeación y desarrollo de estas asignaturas en las generaciones siguientes. Por ello se solicitó a los estudiantes que expresan lo bueno y lo malo del curso, lo que fue de su agrado o no así como las recomendaciones que hacían para el trabajo del profesor; los comentarios de los estudiantes se clasificaron en tres grupos y se muestran en las tablas siguientes:

La tabla 14 muestra que la forma de trabajo del profesor en el desarrollo de los contenidos de las asignaturas económico administrativas fue favorable pues en su mayoría los estudiantes comentaron su nivel de agrado por su desempeño, lo anterior resulta de importancia pues tal como lo comenta Elliot (2000), en la evaluación del desempeño del profesor los estudiantes además de mencionar el dominio técnico que tiene en su área deben incluir las pautas generales que utiliza para llevar a cabo su trabajo en el aula así como la preocupación que manifiesta por el aprendizaje de sus alumnos. Tomando en cuenta lo anterior los estudiantes refieren que el profesor fue paciente y tranquilo en las clases y que el nivel de exigencia fue el adecuado pues tomó 
en cuenta que no son estudiantes del área de negocios y que por lo tanto no les exigió el desarrollo de actividades más allá de los conocimientos básicos de los cursos, todo lo anterior aunado a que los temas fueron abordados con explicaciones muy sencillas y utilizando ejemplos de vivencias laborales personales para la mejor comprensión de los temas.

\section{Tabla 14.}

Comentarios sobre la forma de trabajo del profesor (didáctica).

\section{Didáctica del profesor}

3. Solo me queda agradecerle por ser muy paciente y por lo aprendido, fue una materia dinámica y muy interesante (Paula, IA).

4. El desarrollo de la asignatura fue tranquila y muy amena (Eligio, IB).

5. Su manera de transmitir el mensaje siempre era muy claro y conciso, el compartir sus experiencias laborales apoyando los temas de la asignatura hacia más amena la clase, el interactuar con el grupo pidiendo nuestras opiniones nos hacía pensar sensatamente la respuesta a lo requerido (Rosa, IB).

6. Que el profesor hablaba mucho, ja jajá, mentira, eso fue lo bueno ya que mostró un dominio en la materia y con ello consiguió enseñar de mejor manera, excelente la materia (Leo, IB).

7. Los temas estuvieron muy bien abordados con claras explicaciones (Mayra, IB).

8. Me voy contento con la materia ya que nos facilitó mucho el aprender, con ejemplos claros e interactuando con todos (Jorge, IB).

9. En cada tema se impartía un ejemplo el cual en lo personal fue una manera de tomarle un rumbo o el interés, porque todo era a partir de experiencias vividas lo que permitía ir más allá, es decir llegarse a imaginar en un futuro en esas condiciones (Zenaida, IB).

10. Una empresa consta de un líder y subordinados a cargo, opino que [el profesor] fue un buen líder pues participábamos en clase y nos aclaró muchas cosas que no sabíamos (Keyla, IB).

Fuente: elaboración propia con datos obtenidos de los estudiantes.

Los buenos comentarios sobre la forma de trabajo del profesor según la tabla anterior son el resultado quizás de la serie de recursos didácticos utilizados en el desarrollo de los contenidos de las asignaturas, entendidos estos como "aquellos elementos materiales cuya función estriba en facilitar la comunicación que se establece entre educadores y educandos" (Colom et al, 1988:16). La tabla 15 muestra que desde la opinión de los futuros 
ingenieros el docente preocupado por su aprendizaje se valió de cuatro recursos importantes (Salinas, 2002): el uso de exposiciones apoyadas con videos o películas sobre el tema, dinámicas grupales a fin de que vivenciaran e interiorizaran temas de liderazgo y comunicación efectiva, ejemplos de la forma de organización y funcionamiento de algunas empresas importantes del entorno o contexto local que conocen o identifican los estudiantes y, el material escrito sobre el tema pero con un enfoque en la ingeniería.

\section{Tabla 15.}

Comentarios sobre los recursos didácticos utilizados en clases.

\section{Recursos didácticos}

1. Las clases no se me hicieron tediosas, fue bueno que cada quien expusiera un tema ya que así trabajamos más y también que las clases fueron más explicativas [con videos] que leídas o con diapositivas porque eso aburre (Eliza, IA).

2. Me gustaba exponer ya que así daba a conocer a mis compañeros lo que había entendido del tema y me gustó una parte donde una compañera en su exposición nos puso una dinámica muy padre (Aridaith, IB).

3. El ser didáctico en los temas te hacia desestresarte y relajarte, las exposiciones y las películas o videos lograron hacer que trabajáramos como equipo con otras carreras (Rosa, IB).

4. Me gustó que el profesor nos diera ejemplos sobre los temas abarcados y como se relacionaban con nuestras carreras, además de explicarnos como se organizan algunas empresas de la región (Azucena, IB).

5. Hubo mucha calidad con los temas gracias al cuadernillo de "administración para ingenieros" que nos ayudó a comprender los temas básicos de la administración,... y las dinámicas que realizamos fueron de mucha ayuda (Keyla, IB).

6. Las pequeñas dinámicas que se realizaron ya que por más pequeñas dejaban suficiente conocimiento sobre el tema (Zenaida, IB).

Fuente: elaboración propia con datos obtenidos de los estudiantes.

No obstante que los estudiantes evaluaron de manera satisfactoria el desempeño del docente, en la tabla 16 se muestran los comentarios que desde su imaginario consideran importante que los docentes que imparten asignaturas económicas administrativas en carreras de ingeniería deberían de tomar en cuenta a fin de que los estudiantes logren obtener un mejor aprovechamiento de dichos conocimientos, es decir, tal como lo menciona Feldman (1999), los estudiantes sugieren que los docentes abunden en el uso de cuatro recursos 
didácticos, los primeros tres al interior del aula tales como el uso de más dinámicas grupales para afianzar la comprensión de los temas, fomentar la discusión y debate grupal de los mismos y, desarrollar una microempresa como parte de los trabajos de un proyecto escolar, mientras que para el exterior sugieren que se planeen visitas en algunas empresas del entorno geográfico para que conozcan su forma de organización y funcionamiento y corroboren la relación de los temas económico administrativos con los puestos y funciones de la ingeniería.

\section{Tabla 16.}

Sugerencias para mejorar el proceso de enseñanza aprendizaje.

\section{Sugerencias}

1. Me hubiera gustado que se hicieran más dinámicas para no aburrirse en clase o que los compañeros llevaran imágenes en sus exposiciones ya que solo copiar letra no ayuda mucho, también que los compañeros hubieran dados ejemplos de lo que decían e hizo falta que el auditorio hablara mas no solo el expositor porque si solo una persona habla es muy aburrido escucharla (Eliza, IA).

2. Mis recomendaciones son poner más dinámicas para activar a los chicos y que haya participaciones o sean como un porcentaje para que así participen y pongan más atención, pero también que haya dinámicas como debates entre todo el grupo en equipos pequeños y que todos los grupos den sus puntos de vista (Aridaith, IB).

3. Nos hizo falta un proyecto en equipo para realizar una microempresa, así nos definiríamos como emprendedores, incluso daríamos un ejemplo de cómo se deben realizar dichas tareas (Eligio, IB).

Fuente: elaboración propia con datos obtenidos de los estudiantes.

\section{Discusiones y conclusiones}

El impulso a temas trasversales en la currícula de ingeniería corresponden a las nuevas formas de organización del trabajo que demandan cuadros profesionales polivalentes y flexibles tal como lo mencionan Klink, Boon y Schlusmans (2007), por lo anterior las universidades deben procurar responder a dichas exigencias a través de refuncionalizar a las ingenierías dejando atrás su figura de carrera tradicional con una formación técnica especializada (Damián, 2018; Capote, Rizo \& Bravo, 2016; ASME, 2011;) y hacer las adecuaciones curriculares que garanticen un perfil integral de los futuros ingenieros (Dorador, 2014; Rascón, 2012; Covarrubias, 1998). Diversos estudios de alcance nacional e internacional dejan claro que 
el campo de actuación del profesional de la ingeniera ha cambiado ante los grandes desafíos que enfrenta la humanidad, a los cuales tendrán que encontrar soluciones viables desde el ámbito científico, tecnológico y con un gran sentido de responsabilidad social (UNESCO, 2010, Moreno, 2007; Restrepo, 2007), por lo anterior es necesario que en la formación de los futuros ingenieros se tome en cuenta la dualidad de su demarcación profesional (ingenieros de diseño-ingenieros de gestión), es decir, se debe garantizar que al término de su formación universitaria este profesional cuente con los conocimientos, habilidades y destrezas que le permitan moverse laboralmente en las dos demarcaciones (Álvarez, 2014; ASME, 2011; Smerdon, 2000).

Grupos de especialistas y asociaciones públicas y privadas de las áreas de ingeniería han llegado a consensos sobre los tres componentes que deben integrar la currícula de este tipo de profesional: formativo (ciencias exactas), formación específica (ciencias de la ingeniería) y formación complementaria (ciencias económicas, sociales y humanidades); para responder a los nuevos requerimientos del mundo del trabajo y su forma de organización actual (UNESCO, 2010; Moreno, 2007; ACOFI, 2007); por todo lo antes expuesto actualmente las universidades están empezando a integrar en la currícula de manera específica como de forma transversal diversos tópicos del área económico administrativo. Sin embargo, de acuerdo con los resultados obtenidos en este trabajo se puede afirmar y concluir que es un reto el incorporar este tipo de temas en la currícula de ingeniería tanto para los estudiantes como para los profesores, a los primeros les resulta contradictorio al no estar conscientes de la utilidad y aporte en su formación profesional originando una actitud apática o indiferente ante dichos cursos y, en cuanto a los docentes no están preparados para abordar los contenidos con un enfoque en ingeniería y lo hacen utilizando las mismas estrategias y recursos didácticos que emplean con los estudiantes del área de administración o de negocios, originando una brecha entre los objetivos que persiguen dichas asignaturas con la disposición de aprender de los estudiantes. 
Para superar este reto es necesario que las universidades y las asociaciones de ingenieros emprendan acciones informando a los estudiantes las ventajas y beneficios de estudiar temas económico administrativas y los profesores apliquen estrategias didácticas encaminadas a que los estudiantes de ingeniería modifiquen sus representaciones acerca de dichos cursos y obtengan una opinión favorable considerándolos como una plusvalía al futuro ingeniero (Williams, 2004). De acuerdo con los resultados obtenidos por las acciones emprendidas en el proceso de enseñanza aprendizaje con estudiantes de ingeniería que se describen en este trabajo, se concluye que los retos mencionados se pueden superar si se está consciente de que las universidades públicas deben asumir un papel protagónico en la formación de las nuevas generaciones de futuros ingenieros con una formación polivalente y multidisciplinaria que vaya más allá de la formación meramente técnica y sea un ingeniero sociotécnico (Sáez, 2004; Correia \& Bozutti, 2017).

De manera prospectiva se puede mencionar que los resultados de este trabajo generaron conocimiento que abona a una línea emergente en la investigación educativa, pues se reconoce que poco se ha indagado sobre la situación y el ambiente que prevalece en las aulas con estudiantes de ingeniería durante el proceso de enseñanza aprendizaje al desarrollar temas económico administrativos $\mathrm{y}$, también resulta ser muy escasa la investigación sobre el impacto de los temas transversales del currículo de los programas de ingeniería en el campo de actuación de los ingenieros, lo que bien es indicativo de grandes vetas para generar conocimiento sobre esta temática a través de diversas líneas de investigación. 


\section{Referencias}

ACOFI. (2007). El ingeniero colombiano del año 2020: retos para su formación. Bogotá: Asociación Colombiana de Facultades de Ingeniería.

Allen, T.(1985), Managing the flow of technology. Cambridge: Massachusetts, MIT Press.

Álvarez-Gayou, L. (2005). Cómo hacer investigación cualitativa. Fundamentos y metodología. México: Paidós.

Álvarez, J. (2014). La ingeniería en México. Devenir, estado actual y perspectivas. En N. Adalberto (Coord.). Hacia dónde va la ciencia en México. Ingeniería. México: CONACYT-Academia Mexicana de Ciencias, pp. 19-32.

ASME. (2011). The State of Mechanical Engineering: Today and Beyond. Recuperado de: www.asme.org/getmedia7752441b6-d335-4d93-9722de8dc47321de/State-of- Mechanical-Engineering-Today-and-Beyond. aspx

Ávila, J., \& Cortés, J. (2007). La construcción de las identidades profesionales a través de la educación superior. Cognición, 1(9), 52-62.

Barrón, C. (2005). Formación de profesionales y política educativa en la década de los noventa. Perfiles Educativos, 27(108), 45-69.

Bogdan, R., \& Biklen, K. (1992). Qualitative research for education: An introduction to theory and methods. Boston: Allyn y Bacon

CACEI. (2014). Marco de referencias para la acreditación de los programa de licenciatura en ingeniería (versión 2014). México: Consejo de Acreditación para la Enseñanza de la Ingeniería.

Capote, G., Rizo, N., \& Bravo, G. (2016). La formación de ingenieros en la actualidad. Una explicación necesaria. Revista Universidad y Sociedad, 8(1), 21-28.

Celis, J., \& Gómez, V. (2005). "Factores de innovación curricular y académica en la educación superior" en Revista Electrónica de la Red de Investigación Educativa, 1(2), 1-16.

Colom, A., Sureda, J., \& Salinas, J. (1988). Tecnología y medios educativos. Madrid: Cincel Kapelusz. 
Congregado, E., Hernández, L., Millán, J., Raymond, J., Roig, J., Salas, V., Sánchez, J., \& Serrano, L. (2008). El capital humano y los emprendedores en España. Valencia: Instituto Valenciano de Investigaciones Económicas-Fundación Bancaja.

Correia, S., \& Bozutti, D. (2017). Desafíos y dificultades en la enseñanza de la ingeniería a la generación Z: Un caso de estudio”. Propósitos y Representaciones, 5(2), 127-183. Doi: http://dx.doi.org/10.20511/ pyr2017.v5n2.163

Covarrubias, J. (1998). Tres documentos sobre la formación de ingenieros. Revista Ingenierias, 1(1), 5-9.

Covington, M. (2000). Goal theory, motivation and school achievement: an integrative review. Annual Review of Psychology, 51, 171-200. Doi: https://doi.org/10.1146/annurev.psych.51.1.171

Damián, J. (2018). Habilidades directivas en estudiantes de ingeniería. Casos: Alimentos, Biotecnología y Ciencias Químicas. En V. Hernández et al (comp.), Emprendimiento, Negocios y la Responsabilidad Social en las Organizaciones (pp. 587-608). México: UMSNH.

Damián. J. (2017). Graduates of New University Careers: Unequal Competition on the Labour Market. Propósitos y Representaciones, 5(1), 167-203. doi: http://dx.doi.org/10.20511/pyr2017.v5n1.146

Damián, J. (2016). Professional Identity, Social Recognition and Entering the Workforce of the University Student with Hybrid Education". Propósitos y Representaciones, 2(2), 45-76. Doi: https://doi.org/10.20511/pyr2014. $\mathrm{v} 2 \mathrm{n} 2.60$

Dorador, J. (2014). El futuro de la Ingeniería Mecánica y sus carreras derivadas. En N. Adalberto (Coord.). Hacia dónde va la ciencia en México. Ingeniería. México: CONACYT-Academia Mexicana de Ciencias, pp. 65-73.

Eccles, S., \& Wigfield, A. (2002). Motivational beliefs, values and goals. Annual Review of Psychology, 53, 109-132. Doi: https://doi.org/10.1146/ annurev.psych.53.100901.135153

Elliot, J. (2000). El cambio educativo desde la investigación acción. Madrid: Ediciones Morata. 
Espín, V. (2002). El análisis de contenido: una técnica para explorar y sistematizar información. XXI Revista de Educación, 4, 95-105.

Feldman, D. (1999). Ayudar a enseñar. Relaciones entre didáctica y enseñanza. Argentina: Aique Grupo Editor.

Fox, D. (1981). El proceso de investigación en educación. Pamplona: Eunsa.

García, J., \& Romero, J. (2011). Valoración subjetiva de los atributos que los ingenieros consideran requerir para ocupar puestos administrativos. Un estudio en empresas maquiladoras de Ciudad Juárez". Revista Mexicana de Investigación Educativa, 16(48), 195-219.

Geck, C. (2006). The generation z connection: Teaching information literacy to the newest net generation. Teacher librarian, 33(3), 19-23.

Gibbons, M., Limoges, C., Nowotny, H., Schwartzman, S., Scott, P., \& Trow, M. (1994). The New Production of Knowledge: The Dynamics of Science and Research in Contemporary Societies. Londres: Sage publications.

Gómez, V., Castellanos, J., \& Delgado, N. (2005). Las habilidades integradas del ingeniero mecánico hoy: ¿un desafio? En: $7^{\circ}$ Congreso Iberoamericano de Ingeniería Mecánica. México D. F.

Hernández, R., Fernández, C., \& Baptista, P. (2014). Metodología de la Investigación. México, McGraw-Hi

Hirst, P., \& J. Zeitlin, J. (1991). Flexible Specialization versus Post-Fordism: Theory, Evidence and Policy Implications. Economy and Society, 20(1), 1-56. Doi: https://doi.org/10.1080/03085147300000001

ITESM. (2018). Admisión, carreras profesionales. Recuperado de: http:// admision.itesm.mx

Klink M., Boon J., \& Schlusmans K. (2007). "Competencias y formación profesional superior: presente y futuro". Revista Europea de Formación Profesional, 1(40), 74-91.

Martínez, M. (2004). La psicología humanista. Un nuevo paradigma psicológico. México: Trillas.

Martínez, K., Damián, J., \& Rodríguez, G. (2018). Evaluación del nivel de aplicación de competencias específicas empleadas durante las estancias profesionales, en V. Hernández, E. Galeana, M. Valenzo y P.Chávez (coord.). Emprendimiento, negocios y la responsabilidad social en las 
organizaciones. México: Universidad Michoacana de San Nicolás de Hidalgo. pp. 695-716.

MEC. (1985). El Mercado de titulados universitarios. Madrid: Ministerio de Educación y Ciencia.

Meijers, F. (1998). The development of a career identity". International Journal for the Advancement of Counselling, 20, 191-207.

Moreno, I. (2007). Consideraciones para una enseñanza de calidad en ingeniería. Revista Pedagogía Universitaria, 12(1), 38- 46.

Murillo,H.(2010). Misión del docente: propiciar en el estudiante aprendizajes significativos. Enfermería universitaria, 7(4), 42-52.

Neffa, J. (1993). Las nuevas tecnologías y sus efectos sobre el empleo a nivel macroeconómico en un contexto de crisis y reconversión. Ajuste estructural, cambio tecnológico y Empleo, OEI, s/p.

Pastor, J., Peraita, C., \& Zaera, I. (2013). Expectativas laborales y de futuro de los universitarios españoles. XXII Jornadas de la Asociación de Economía de la Educación. A Coruña.

Pérez, F., Serrano, L., Pastor, J., Hernández, L., Soler, A., \& Zaera, I. (2012). Universidad, universitarios y productividad en España. Bilbao: Fundación BBVA.

Rascón, O. (2012). Panorama de la Ingeniería en México y el Mundo. Documento de trabajo. México. CONACYT-Academia de Ingeniería de México.

Rodríguez, J. (1995). Exigencias educativas de la producción flexible. En Rodríguez et al. (coord.). Volver a pensar la educación. España: Ediciones Morata, 371-385.

Romero, L. (2013). Un perfil emprendedor como respuesta a la saturación del mercado de trabajo. El caso de las carreras de ciencia y tecnología de la Universidad del Papaloapan (Tesis de licenciatura). Universidad del Papaloapan, México.

Romero, L., Utrilla A., \& Utrilla, V. (2014). Las actitudes positivas y negativas de los estudiantes en el aprendizaje de las matemáticas, su impacto en la reprobación y la eficiencia terminal. Ra Ximhail, 10(5), 291-319. 
Ruiz, E. (2004). Ingenieros en la industria manufacturera. Formación, profesión y actividad laboral. México: Plaza y Valdés - UNAM.

Ruiz, E. (1998). La era pos-industrial y la formación de ingenieros. Perfiles Educativos, 79(80), 58-79.

Sáez, F. (2004). Futuros ingenieros híbridos. Revista BIT, 144, 7-9.

Salinas, J. (2002). Medios didácticos para una nueva universidad. Recuperado de http://gte.uib.es/pape/gte/sites/gte.uib.es.pape.gte/files/MEDIOS\%20 DID \%C 3\%81CTICOS\%20PARA \%20UNA\%20NUEVA \%20 UNIVERSIDAD.pdf

Salcedo, H. (2011). Los objetivos y su importancia para el proceso de enseñanza-aprendizaje. Revista de Pedagogía, 32(91), 113-130.

Seara, M. (2010). Un nuevo modelo de Universidad. Universidades para el desarrollo. México: Universidad Tecnológica de la Mixteca.

SEP. (2015). Propuesta de modelo de formación para los ingenieros mexicanos. México: SEP-SES.

Smerdon, E. (2000). An Action Agenda for Engineering Curriculum Innovation, presented at the 11th IEEE-USA Biennial Careers Conference, San Jose, Cal., Nov. 2 and 3. Recuperado de: http://www. ieeeusa.org/careercon/proceeding/esmerdon.pdf

Tang, J. (2000). Doing engineering. Lanham: Maryland, Rowman \& Littlefield Publishers.

Tapia, J. (2005). Motivación para el aprendizaje: la perspectiva de los alumnos. En Ministerio de Educación y Ciencia. La Orientación escolar en los centros educativos, 209-242.

Teichler, U. (1998). Las Exigencias del Mundo del Trabajo. Alemania: Organización Internacional del Trabajo (OIT).

UNESCO. (2010). Engineering: Issues, challenges and opportunities for development. France: United Nations Educational, Scientific and Cultural Organization. 
Vega, L. (2013). La educación en ingeniería en el contexto global: propuesta para la formación de ingenieros en el primer cuarto del Siglo XXI. Ingeniería, investigación y tecnología, 14(2), 177-190.

Williams, R. (2004). Cultura y cambio tecnológico: el MIT. Estados Unidos: Alianza Editorial. 